\title{
Philosophy of Modeling: Neglected Pages of History
}

\author{
Karlis Podnieks \\ Faculty of Computing, University of Latvia \\ Raina bulv. 19, Riga, LV-1586, Latvia \\ karlis.podnieks@lu.lv
}

\begin{abstract}
Of the substantial work done in the philosophy of modeling by Vaihinger (1876), Craik (1943), Rosenblueth and Wiener (1945), Apostel (1960), Minsky (1965), Klaus (1966) and Stachowiak (1973), only Vaihinger's work has gained some recognition in the mainstream literature. However, the work of all these thinkers seems to contain original ideas worth discussing. For example, the diverse functions of models in science can be better structured as follows: in fact, models perform only a single function - they are replacing their target systems but for different purposes. Or, the idea that all of cognition is cognition in models or by means of models: even perception can be best analyzed as modeling. Or, the idea that the possibility of modeling is built into the structure of the physical universe: it contains recurrent patterns that can play the roles of models and target systems. The paper presents an analysis of the above-mentioned neglected work.
\end{abstract}

Keywords: modeling, models, means of model-building, theories and models, Vaihinger, Craik, Apostel, Minsky, Stachowiak, Klaus

\section{Introduction}

For a unique exposition of the history of modeling (and the very term "model"), from the ancient mythologies on - see Müller (1983, an extended version of the paper and English translation are available online). Of the pre-1975 proponents of general philosophies of modeling, Müller mentions Hans Vaihinger, Leo Apostel, Patrick Suppes, Georg Klaus and Herbert Stachowiak. Only Stachowiak's approach is acknowledged as, indeed, a general philosophy of modeling, and is represented in some detail.

However, Stachowiak's work is completely ignored by philosophers writing in English. His book "Allgemeine Modelltheorie" was published by Springer Verlag in 1973. A 
book named "General Theory of Models" published in the West, and yet it has gone completely unnoticed.

Similarly, in a prominent account of the philosophy of modeling written by Frigg and Hartmann (2012), of the pre-1975 proponents of general philosophies of modeling only the following are mentioned: Vaihinger, Apostel, Mary Hesse and Suppes, with only Hesse and Suppes receiving due honor.

However, the first version of a general philosophy of modeling was proposed in Vaihinger's book "Die Philosophie des Als Ob" (written in 1876, published in 1911). How could it happen that his grave in Gertraudenfriedhof in Halle, Germany, is "abandoned" [aufgelassen]? (Wikipedia 2018).

Kenneth Craik in his book "The Nature of Explanation" (1943) proposed a general philosophy of modeling, covering mathematical and theoretical models of any scale but this advanced and general aspect of Craik's philosophy is almost completely ignored. Craik's contribution to philosophy is only somewhat acknowledged as a precursor of small-scale mental model theories of everyday reasoning.

These, and other neglected pages of the history are presented in Section 3 below. For a better orientation, Section 2 contains a summary of some of the ideas and distinctions referenced in Section 3.

\section{Philosophy of modeling: some ideas and distinctions}

\section{Models as replacements}

When people try to propose a unifying answer to the question "What are models?", they are forced to account for the diverse uses of the term "model" in science. Thus, for example, Leo Apostel started his seminal paper (1960) by recognizing nine of the "main motives underlying the use of models". However, at the end of the paper Apostel proposed (as a "hint") the first unifying idea (details below). The diverse functions of models can be better structured as follows: in fact, models perform only a single function - they are replacing their target systems but for different purposes.

Much later, Jeff Rothenberg (1989) proposed an elegant concise formulation of this idea:

"Modeling in its broadest sense is the cost-effective use of something in place of something else for some cognitive purpose." (p. 75)

Isn't this idea worth discussing?

Note. According to the above approach used in science, set-theoretical models of formal theories used in mathematical logic do not function as models with respect to their theories (as noted by Stachowiak (1973), p. 3-4). These "models" do not replace their theories. It would be better to call them interpretations (implementations, instances) of theories, but not models. But, of course, set-theoretical interpretations of theories may serve as models-replacements of empirical target systems, as proposed by Suppes (1960) in the so-called semantic view of theories. 


\section{Cognition as modeling}

Another principal idea was proposed by Stachowiak (1973):

"Hiernach, ist alle Erkenntnis Erkenntnis in Modellen oder durch Modelle, und jegliche menschliche Weltbegegnung überhaupt bedarf des Mediums "Modell”: ...” ( p. 56)

"Therefore, all of cognition is cognition in models or by means of models, and in general, any human encounter with the world needs "model" as the mediator: ..."

Stachowiak called this approach "the model-based concept of cognition" [das Modellkonzept der Erkenntnis], or "modelism" [Modellismus, details below].

As a hypothesis, this idea was proposed already by Craik (1943):

"It is generally agreed that thought employs symbols such as written or spoken words or tokens; but it is not generally considered whether the whole of thought may not consist of a process of symbolism, nor is the nature of symbolism and its presence or absence in the inorganic world discussed." (p. 58, my emphasis added)

Craik used "process of symbolism" as a synonym for modeling (details below).

Thus, models are ubiquitous in cognition. Even perception, reflexes and animal instincts can be best analyzed as modeling. "Cognition is modelism."

Isn't this second idea worth discussing as well?

\section{Theories as means of model-building}

The third idea: if we need models, we need also means of model-building. Theories ("theoretical laws") are less "noble" than they are usually understood. The principal purpose and function of theories is model-building. In all of its generality, this idea was introduced by Nancy Cartwright (1983) as "a simulacrum account of explanation":

\footnotetext{
"The appearance of truth [of fundamental laws] comes from a bad model of explanation, a model that ties laws directly to reality. As an alternative to the conventional picture I propose a simulacrum account of explanation. The route from theory to reality is from theory to model, and then from model to phenomenological law. The phenomenological laws are indeed true of the objects in reality - or might be; but the fundamental laws are true only of objects in the model." (p. 4)
}

More specific versions of this idea were proposed earlier by Suppes (1960), Apostel (1960), Mario Bunge (1969, 1973, p. 42-47) and Ronald Giere (1979, p. 80-81). However, I would invite the actual participants of the story to provide a more detailed account.

Two extreme kinds of modeling

The simplest kind of modeling is creating models of fully observable target systems, by omitting the details that are not important for the purpose of modeling (abstraction) 
or by replacing complex structures with simpler ones (idealization). The relationship of such models to their targets is expressed as isomorphism, homomorphism, similarity, etc. Let us call this extreme kind modeling-by-simplification.

More sophisticated kinds of modeling involve setting not-fully-observable structures behind the observable picture, for instance, epicycles, heliocentric system, elliptic orbits, gravitation, molecules, atoms, electrons, photons, protons, quarks, tectonic plates, black holes, Big Bang, human evolution, DNA, Late Bronze Age collapse, Vandalic language, assassination of John F. Kennedy, etc. Such structures cannot be fully discovered: their non-observable parts can only be invented (or, derived from other inventions). As put by Albert Einstein (1930, another neglected page?):

\footnotetext{
"It seems that the human mind has first to construct forms independently, before we can find them in things. Kepler's marvelous achievement is a particularly fine example of the truth that knowledge cannot spring from experience alone, but only from the comparison of the inventions of the intellect with observed fact."
}

Let us call this second extreme kind modeling-by-invention. Here, the relationship of invented models to their targets is more complicated than isomorphism, similarity etc.

\section{Philosophy of modeling: neglected pages of history}

\subsection{A tribute to Hans Vaihinger (1876)}

Vaihinger proposed a radical further step along the line of thought developed by Plato, Berkeley, Hume and Kant: let us recognize that all knowledge, "if it goes beyond simple actual succession and co-existence" of sensations, consists of selected imperfect human inventions (fictions).

The first edition of Vaihinger's book "Die Philosophie des Als Ob" was published in 1911. However, its principal chapters (Part I) reproduce parts of Vaihinger's Habilitationsschrift written during the autumn and winter months of 1876 (at the age of 24). Part I is extended by Part II, which is based on texts written during 1877-1879, when Vaihinger started to prepare a book. However, the project was interrupted for about 25 years, and was only completed in 1911. For more details, see Fine (1993) and Simon (2014).

The idea that Vaihinger's "fictionalism" is relevant to the philosophy of modeling is due to Fine:

"Preeminently, the industry devoted to modeling natural phenomena, in every area of science, involves fictions in Vaihinger's sense. If you want to see what treating something "as if" it were something else amounts to, just look at most of what any scientist does in any hour of any working day." (p. 16)

"... the dominant self-conception of postwar science has been that of sciences as the builder of useful models. Vaihinger was surely the earliest and most enthusiastic proponent of this conception, the preeminent twentieth-century philosopher of modeling." (p. 
For a similar conclusion, see Suárez (2009):

"Vaihinger's work is unfortunately not sufficiently well known today, but he should appear to philosophers of science as an extremely contemporary figure." (p. 158)

Thus, some philosophers of science already are analyzing Vaihinger's work with consideration. However, I think, he deserves more.

I am preparing a separate paper "A Tribute to Hans Vaihinger". The summary (somewhat purified of Vaihinger's inconsistencies and faults) is as follows: Vaihinger's 1876 "fictionalism" was, in fact, the first explicitly formulated general philosophy of modeling.

Vaihinger's 1911 tribute to Friedrich Nietzsche

In Part III of his book, Vaihinger presented an analysis of the ideas proposed by Friedrich Nietzsche within the philosophy of science, morality and religion. Nietzsche himself named his approach "perspectivism". Vaihinger's conclusion: Nietzsche had in fact independently proposed a version of Philosophie des Als $\mathrm{Ob}$.

\subsection{A tribute to Kenneth Craik (1943)}

Craik's book "The Nature of Explanation" (1943) was published two years before his untimely death at the age of 31 . As we will see below, this small book contained, in fact, an advanced general philosophy of modeling, covering mathematical and theoretical models of any scale. However, this advanced work is largely ignored by the community of philosophers of science. Craik's contribution to philosophy is only somewhat acknowledged as a precursor of small-scale mental model theories of everyday reasoning - the line of thought started by Johnson-Laird (1980).

For an account of the historical context of Craik's work, see Gregory (1983). Craik's book was

"written just before the impact of digital computers, so Craik necessarily based his ideas on analog devices." (p. 233)

The summary of Craik's proposal is expressed strikingly at the end of the book:

"Assuming then the existence of the external world I have outlined a symbolic theory of thought, in which the nervous system is viewed as a calculating machine capable of modelling or paralleling external events, and have suggested that this process of paralleling is a basic feature of thought and of explanation. The possessor of a nervous system is thus able to anticipate events instead of making invariable empirical trial." (p. 120-121, my emphasis added)

In the Preface, Craik calls this proposal "the 'paralleling' theory of thought" (p. VIII), and in the Postscript - "the 'modelling' theory of thought" (p. 124). 
In the "Introduction. The present state of philosophy", Craik proposes to apply the wellknown scientific procedure in philosophy: "induction supported by experiments to test hypotheses" (p. 1).

In Ch. I "The function and the importance of explanation", Craik does not explain what explanation is, only describing it as a phenomenon, and mentions "five main attitudes" to it: apriorism, skepticism, descriptive theories, relational theories (quantum mechanics), and (his preference) causal theories (p. 7-8, i.e. theories based on what I would call the causal paradigm).

In Ch. II "A priorism and scepticism", Craik analyzes the first two attitudes, the philosophical principles proposed by Descartes, Hume, Berkeley, Whitehead and Ayer. His extremely radical analysis leads to the conclusion that all principles pretending to be valid a priori can only be "dogmatically asserted". When "carefully followed out", all attempts to justify their absolute validity not only fail, but show "the greatest ignorance of the real nature of things" (p. 25).

Complete skepticism is usually criticized as a self-refuting position (although see Stegmüller's (1954) counter-argument, details below). However, Craik's assessment is even more radical: complete skepticism, taken seriously ("carefully followed out"), can be "reduced to silence" (p. 26), because one cannot allow complete skeptics to use human language to express their opinions:

" Thus the use of language itself is based on the principle that any symbolism which works has objective validity; and it is illegitimate to use words to contradict this principle." (p. 27)

As an alternative to dogmatism and skepticism, Craik proposes to rely on "symbolisms that work", such as human language:

"Thus we do not try to prove the existence of the external world - we discover it, because the fundamental power of words or other symbols to represent events ... permits us to put forward hypotheses and test their truth by reference to experience. ... A particular type of symbolism may always fail in a particular case, as Euclidean geometry apparently fails to represent stellar space; but if all types of symbolism always failed, we should be unable to recognise any objects or exist at all.” (p. 29)

Throughout the book, Craik applies the term "symbolism" to means of model-building: theories, mathematical structures and human language.

Craik's consideration of human language as an experimentally-established successful means of model-building should be qualified as an extremely advanced demystifying idea.

Unfortunately, Ch. III "Relational and descriptive theories" can be used by critics to discredit Craik as a modern thinker. Here, he protests against applying quantum theory in its current (as of 1943) state to draw the ultimate conclusion that indeterminism is "a characteristic of real phenomena":

"I am not trying to belittle the achievements of quantum mechanics in covering and predicting phenomena." (p. 38) 
"There is only a difference in attitude to microscopic events where most quantum physicists regard indeterminism as a characteristic of real phenomena and I (tentatively, because I am unable to follow the mathematical detail of their theories) do not." (p. 30)

The first argument:

"Neither the limit of observation imposed by the disturbing influence of the observing electron or quantum, nor the intangible nature of the conception of a wave-particle justifies us, surely, in imposing on reality the burden of supporting the short-comings of our own intellects and instruments." (p. 32)

"I am only asking them [physicists] to refrain from saying that reality must have the same limitations as their methods of observation. Science surely is an attempt to find out the nature of reality by experiment, theoretical formulation of hypotheses, and verification; not an attempt to assert that reality has the same limitations as our methods of observation.” (p. 39)

The second argument: according to Craik's intuition, there must be some "real" causal mechanism (we would say, some local hidden variable mechanism), to be discovered later, behind the probability distributions of quantum theory. His line of argument shows that he is treating quantum probabilities in the classical way (as a probability space obeying Kolmogorov axioms). However, despite the naivety of his arguments, Craik is here in good company with Einstein, Podolsky and Rosen.

In Ch. IV "On causality" Craik continues to argue in favor of his belief in the causal paradigm as a potentially universal means of model-building:

"I do not mean that it [Craik's argument] is a way of demonstrating [by a "logical proof"] the existence of causality, but only that it shows some of our words and concepts to be so pervaded and saturated with causality that no formal analysis, however rigorous, will rid them of causality...” (p. 42).

“... most of the great hypotheses and experiments of Newton, Maxwell, Rutherford, Darwin and the rest have been inspired by the idea of tracing the action of causes in nature." (p. 46)

“... we are admittedly unable to probe causation to the bottom and find ultimate links and a first cause; but this limitation on our thought ... is no sufficient reason for rejecting the idea that reality may be constituted in this [i.e. causal] way. We should try out the idea as long as it works and suggests definite consequences." (p. 47)

Thus, Craik rejects both naive realism and complete skepticism, while he is aware that the causal paradigm cannot be justified "logically", in the absolute sense many people are awaiting. But "we should try [it] out as long as it works". As noted by Barrett (2001), Charles Sanders Peirce in his seminal papers $(1877,1878)$ considered the entirety of science as a temporarily consistent system of such working constructs.

In the central chapter of the book - Ch. V "Hypothesis on the nature of thought", Craik takes "the existence of the external world and of causation for granted" and is "advancing a hypothesis" (p. 50). Namely: 
"My hypothesis then is that thought models, or parallels, reality - that its essential feature is not 'the mind', 'the self', 'sense-data', nor propositions but symbolism, and that this symbolism is largely of the same kind as that which is familiar to us in mechanical devices which aid thought and calculation." (p. 57)

Craik uses the verbs "model", "parallel", "imitate", and the nouns "modelling", "paralleling", "symbolisation" as synonyms. However, Craik's "symbolisation" possesses more a flavor of means of model-building.

The starting point of his argument: "One of the most fundamental properties of thought is its power of predicting events." "Here there are three essential processes": translation, reasoning and re-translation. "External processes" are translated into "words, numbers or other symbols"; after this, reasoning arrives at "other symbols", which are re-translated back into "external processes" (p. 50). The next step of the argument - a mechanical analogy:

"Surely, however, this process of prediction is not unique to minds, though no doubt it is hard to imitate the flexibility and versatility of mental prediction. A calculating machine, an antiaircraft "predictor," and Kelvin's tidal predictor all show the same ability." (p. 51)

These imitative "mechanical devices or models" are "cheaper, or quicker, or more convenient in operation" (p. 51).

At this point, Craik introduces his definition of physical (material) models:

"By a model we thus mean any physical or chemical system which has a similar relationstructure to that of the process it imitates. By 'relation-structure' I do not mean some obscure non-physical entity which attends the model, but the fact that it is a physical working model which works in the same way as the process it parallels, in the aspects under consideration at any moment." (p. 51)

He immediately transfers this definition from physical models to "neural machinery":

“... I have tried, in the succeeding pages, to indicate what I suspect to be the fundamental feature of neural machinery - its power to parallel or model external events - and have emphasised the fundamental role of this process of paralleling in calculating machines." (p. 52)

"Without enquiring into the relation between such neural patterns and the unitary symbols of thought - words, numbers, etc. - we can study to some extent the scope and limits of this modelling or imitative process, by studying the scope and limits of the two great classes of symbols - words and numbers." (p. 53)

About Craik's demystifying approach to the first of these classes of symbols - words, see above: he considers human language as an experimentally-established successful means of model-building.

Craik's approach to the second class of symbols - numbers is demystifying as well: 
"Perhaps the extraordinary pervasiveness of number, and the multiplicity of operations which can be performed on number without leading to inconsistency, is not a proof of the 'real existence' of numbers as such, but a proof of the extreme flexibility of the neural model or calculating machine. This flexibility renders a far greater number of operations possible for it than for any other single process or model." (p. 53-54)

"We have now to enquire how the neural mechanism, in producing numerical measurement and calculation, has managed to function in a way so much more universal and flexible than any other. Our question, to emphasize it once again, is not to ask what kind of thing a number is, but to think what kind of mechanism could represent so many physically possible or impossible, and yet self-consistent, processes as number does." (p. 55)

See also p. 75-76 in Ch. VI.

Thus, Craik proposes another advanced demystifying idea: "numerical symbolism" is ubiquitous in modeling not because of the "real existence" of numbers, but because, as a structure, numbers represent a "much more universal and flexible mechanism than any other".

Craik is unique also in asking and answering the question: why, at all, is modeling/ paralleling possible?

\begin{abstract}
"Of course we have still to face the question why these analogies between different mechanisms - these similarities of relation-structure - should exist. To see common principles and simple rules running through such complexity is at first perplexing though intriguing. When, however, we find that the apparently complex objects around us are combinations of a few almost indestructible units, such as electrons, it becomes less perplexing." (p. 54)

"This, however, is very speculative; the point of interest for our present enquiry is that physical reality is built up, apparently, from a few fundamental types of units whose properties determine many of the properties of the most complicated phenomena, and this seems to afford a sufficient explanation of the emergence of analogies between mechanisms and similarities of relation-structure among these combinations without the necessity of any theory of objective universals." (p. 55)

"Without falling into the trap of attempting a precise definition, we may suggest a theory as to the general nature of symbolism, viz. that it is the ability of processes to parallel or imitate each other, or the fact that they can do so since there are recurrent patterns in reality." (p. 58-59, my emphasis added)
\end{abstract}

Thus, in modern terms, the possibility of modeling is built into the structure of the physical universe. Fragments of the universe (models) are "working in the same way in certain essential respects" as some other fragments of the universe (target systems). The advantage of "neural modeling" (my term imitating Craik's terminology):

"It is likely then that the nervous system is in a fortunate position, as far as modelling physical processes is concerned, in that it has only to produce combinations of excited arcs, not physical objects; its 'answer' need only be a combination of consistent patterns of excitation - not a new object that is physically and chemically stable." (p. 56) 
"Mental prediction" in the passage on p. 51 quoted above is the only occurrence of the term "mental" in Ch. V. The term "neural" is used much more -8 times: neural machinery, neural pattern (5 times), neural model, neural mechanism. From the very beginning of Ch. V (talking about designing of bridges on p. 50), we see that, for Craik, "neural modeling" includes theoretical and mathematical modeling of any scale, all of science, and not only small-scale mental models used in everyday reasoning.

"It is generally agreed that thought employs symbols such as written or spoken words or tokens; but it is not generally considered whether the whole of thought may not consist of a process of symbolism, nor is the nature of symbolism and its presence or absence in the inorganic world discussed." (p. 58, my emphasis added)

The general picture:

"Thus there are instances of symbolisation in nature; we use such instances as an aid to thinking; there is evidence of similar mechanisms at work in our own sensory and central nervous systems; and the function of such symbolisation is plain. If the organism carries a 'small-scale model' of external reality and of its own possible actions within its head, it is able to try out various alternatives, conclude which is the best of them, react to future situations before they arise, ...” (p. 61, my emphasis added)

Instead of the usual rejection of this hypothesis from the very beginning as implausible, Craik proposes to find out experimentally where exactly it fails (if it fails).

In Ch. VI "Some consequences of this hypothesis", Craik's modeling hypothesis,

“... is tentatively applied to a number of philosophical and psychological problems (such as paradox and illusion) where ontological explanations, in my [Craik's] opinion, have failed.” (p. 121)

Craik is trying to counter a number of arguments against his theory. In the simplest cases he does this by showing mechanical analogs to phenomena seemingly unique to human minds.

Problems, considered in Ch. VI, listed in order of appearance:

meaning (meaningfulness, reference); parallelism of implication and causality; recognition of identity and similarity; adaptation; differentiation; conscious and unconscious processes; measurement and numbers in modeling; possible neural correlates of numbers; hypostatisation and naive realism; our internal working model of reality (p. 82-83); the whole, its parts and the problem of emergent evolution; memory and the power to learn; dangers of introspection; conscious and automatic processes; thought and feelings; selfishness and hedonism; difficulties with classical ethics; hysterical conduct and wishful thinking; errors of perception (illusions); errors of thought (paradoxes); possible limitations of thought "to represent in itself microscopic phenomena" (p. 95, because the causal paradigm is so strongly built into our thinking); pleasure and frustration; materialism and dogmatism; immortality of soul; Craik's specific cognitive optimism (p. 99). 
"Our theory has some bleaker consequences.... What is knowledge, if we are but a part of the mechanical system of the world we seek to know? What becomes of our ceaseless effort to explain the universe we live in, if explanation is but a part of the mechanical process?" (p. 97)

"This is the one form of intolerance I heartily approve - an intolerance for those who will not try experiments but prefer to be dogmatic, whether dogmatic materialists or dogmatic vitalists." (p. 98)

Craik's specific cognitive optimism:

“... there is something wonderful in the idea that man's brain is the greatest machine of all, imitating within its tiny network events happening in the most distant stars, ... On our model theory neural or other mechanisms can imitate or parallel the behaviour and interaction of physical objects and so supply us with information on physical processes which are not directly observable to us." (p. 99)

Ch. VII "Methods of testing this hypothesis. Discussion of possible criticisms. Summary" continues Ch. VI by considering further the following problems: the meaning of "meaning", three types of meaninglessness, various types of proof, deductive proof, ideal objects and mathematical Platonism (p. 107).

“... does this perfect precision [of geometrical reasoning], not to empirical objects but to ideal objects, indicate some transcendent power of thought, inimitable by mechanical models, and grasping eternal realities as was supposed by Platonics?” (p. 107)

Craik rejects this kind of Platonism by proposing a strange replacement:

'... the apparent precision of geometrical reasoning in dealing with external objects such as triangles does not indicate transcendence of the empirical; it only means that the extreme and most clear-cut instances are chosen in the external world and are symbolised by concepts ..." (p. 107)

Thus, triangles and other geometrical objects are copies of some ("most clear-cut") empirical objects and not idealizations? It appears, Craik does not notice that ideal objects created by idealization, speaking strictly, do not exist in the empirical world. And that theorems proved about ideal objects, being "nearly true", are "literally false" in this world. This seems strange because Craik is aware that "Euclidean geometry apparently fails to represent stellar space" (p. 29), that classical mechanics is "slightly inapplicable to 'real' force, mass and velocity" because of "relativity effects" (p. 4), that there are "misleading ... over-simplified models" (p. 108) and "wrong theories" (p. $111,117)$, and that if something works, then some other things do not work. On p. 5152 Craik even formulates (I would call it) an "under-determination" thesis for physical models: 
"Thus, the model need not resemble the real object pictorially; Kelvin's tide predictor, which consists of pulleys on levers, does not resemble a tide in appearance, but it works in the same way in certain essential respects - it combines oscillations of various frequencies so as to produce an oscillation which closely resembles in amplitude at each moment the variation in tide level at any place." (p. 51-52)

At a more general level, the situations when several models are possible, are considered on p. 108-109.

Ch. VII is continued by considering further problems:

why do we tend so continually to 'classify' reality into objects; oversimplified models; role of analogies in modeling; situations when several models are possible [underdetermination?]; emotional "predjudices against admitting how much mechanism can do", why the simplest explanation (i.e. the one based on fewer new postulates) is most likely to be true; why seeking for mechanisms behind phenomena is more productive than trying to explain more complicated facts in terms of these phenomena as 'forces'; neural associations in the brain.

On p. 116-120 and in the Postscript, Craik comments somewhat ironically on the attempts of sweeping criticism of his theory from the position of a naive dualism of mind and body.

To conclude, let us repeat once again: Craik's conception covers theoretical and mathematical modeling of any scale, all of science, and not only small-scale mental models used in everyday reasoning. It represents an attempt of a general philosophy of modeling.

\subsection{Arturo Rosenblueth and Norbert Wiener (1945)}

In their paper (1945), Rosenblueth and Wiener (a physiologist and a mathematician) recognized replacing as the principal feature of modeling, and the ubiquitous role of modeling in science; they do so, however, with an emphasis on modeling-by-simplification:

"No substantial part of the universe is so simple that it can be grasped and controlled without abstraction. Abstraction consists in replacing the part of the universe under consideration by a model of similar but simpler structure. Models, formal and intellectual on the one hand, or material on the other, are thus a central necessity of scientific procedure." (p. 316, my emphasis added)

At the end of the paper, a feeling is expressed, similar to the Dappled World Perspective proposed by Cartwright (1999):

"Partial models, imperfect as they may be, are the only means developed by science for understanding the universe. This statement does not imply an attitude of defeatism but the recognition that the main tool of science is the human mind and that the human mind is finite." (p. 321) 


\subsection{A tribute to Leo Apostel (1960)}

With Apostel's (1960) paper begins the modern history of attempts to give a unifying and explicit answer to the question "What are models?":

"Scientific research utilises models in many places, as instruments in the service of many different needs. The first requirement a study of model-building in science should satisfy is not to neglect this undeniable diversity (as has sometimes been done), and, when recognising this multiplicity, to realise that the same instrument cannot perform all those functions (often the multiplicity of function is recognised but either not to a full extent, or not with respect to the difference of structure it implies)". (p. 1)

Apostel starts the paper by describing nine of the "main motives underlying the use of models" in scientific practice. For instance, the first motive in his list:

“(A) For a certain domain of facts let no theory be known. If we replace our study of this domain by the study of another set of facts for which a theory is well known, and that has certain important characteristics in common with the field under investigation, then we use a model to develop our knowledge from a zero (or near zero) starting point." (p. 1, my emphasis added)

For example, a model might be selected or built to represent some object, if the latter

“... is too big or too small or too far away or too dangerous to be observed or experimented upon.” (p. 2)

Rothenberg (1989) expressed this idea as the requirement of the "cost-efficiency" of modeling.

For another example, the last of the nine motives (a correct feeling of the theory-model relationship):

"(I) It often occurs that the theoretical level is far away from the observational level; concepts cannot be immediately interpreted in terms of observations. Models are then introduced to constitute the bridge between the theoretical and observational levels, the theoretical predicates being interpretable as predicates of the model and the observational predicates being also interpretable as predicates of the model, the model furnishing lawful relationships between the two interpretations. This intermediary model can be used to construct the abstract theory or, once it exists, to find for it domains of application.” (p. 2-3, my emphasis added).

As one of the problems caused by the diversity of functions of models, Apostel stated:

"(iv) Can some common feature be distinguished, either among the various aims, or among the various eventual structures, thus unifying to some extent the family of models?" (p. 3, my emphasis added) 
To start solving the problem,

"Let then $\mathrm{R}(\mathrm{S}, \mathrm{P}, \mathrm{M}, \mathrm{T})$ indicate the main variables of the modelling relationship. The subject $\mathrm{S}$ takes, in view of the purpose $\mathrm{P}$, the entity $\mathrm{M}$ as a model for the prototype T." (p. 4)

Thus, according to Apostel, modeling is not a binary relationship between the model $\mathrm{M}$ and its target system T, but a four-part one, involving the subject (model user) $\mathrm{S}$ and the purpose $\mathrm{P}$ of modeling. He considers his list of motives (functions of models) as a classification of purposes.

At the very end of the paper, Apostel proposes the idea that replacing (already mentioned throughout the paper) could be the common distinguishing feature of all the seemingly different "functions of models":

"This will be our final and most general hint towards the definition of model: any subject using a system $A$ that is neither directly nor indirectly interacting with a system $B$ to obtain information about the system $B$, is using $A$ as a model for $\mathrm{B}$. The definition of 'using', 'purpose' and 'information about' are problems formal pragmatics is already beginning to tackle. While we do not think that this type of definition of the model concept is very fruitful (the syntactical, algebraic and semantic study of the various special model concepts seem to us immensely more fruitful), we are convinced at least that a general definition along these lines is possible, adequate and formal.” (p. 36-37)

Indeed, most of the middle part of Apostel's paper is devoted to this "syntactical, algebraic and semantic study" of models. A similar tendency is shown by Stachowiak (1973): a considerable percentage of his pages is devoted to formal aspects of modeling (e.g. attribute mapping).

\subsection{Marvin Minsky (1965)}

Minsky emphasized, definitely and explicitly, replacing and purpose as the principal features of modeling: $A^{*}$ is a model of $A$, if one can use $A^{*}$ in place of A to answer questions about A. This simple definition was proposed in Minsky (1965):

"If a creature can answer a question about a hypothetical experiment without actually performing it, then it has demonstrated some knowledge about the world. For, his answer to the question must be an encoded description of the behavior, inside the creature, of some sub-machine or model responding to an encoded description of the world situation described by the question. We use the term "model" in the following sense:

To an observer $B$, an object $A *$ is a model of an object $A$ to the extent that $B$ can use $A^{*}$ to answer questions that interest him about $A$.

The model relation is inherently ternary. Any attempt to suppress the role of the intentions of the investigator B leads to circular definitions or to ambiguities about essential features and the like." (p. 45)

In an earlier paper (1961), Minsky was already extensively using this notion of model, but without an explicit definition. Minsky referred to Craik (1943), but did not mention Apostel. 


\subsection{A tribute to Georg Klaus (1966)}

Cybernetics-oriented East German philosopher Georg Klaus tried to propose modeltheoretic arguments in favor of the epistemology of dialectical materialism. These arguments are analyzed in Section 2.4.2 of Stachowiak (1973). Klaus's book "Kybernetik und Erkenntnistheorie" (1966, "Cybernetics and Epistemology") is enlightening even today, and is still worth reading. Consider, for example, his cybernetical assessment of Kant's apriorism on p. 34-37, where he concludes that a priori schemas "have come into being historically" [sind geschichtlich entstanden, p. 34], and hence are, in fact, only "relative a priori". Consider also the excellently-written Section 3.3 "Invariantenbildung" (p. 65-67):

"Die unmittelbare Aufgabe unseres Erkenntnisapparates besteht in der Bildung von Invarianten, und zwar von Invarianten der Wahrnehmung, des Denkens und der Motive." (p. 65)

"The direct task of our cognitive apparatus is the formation of invariants, and namely invariants of perception, thinking and motives."

"Dennoch sind es gerade diese Invarianten, die, kybernetisch gesprochen, eine Stabilisierung des Verhältnisses zwischen Mensch und Umgebung und zwischen den Menschen selbst überhaupt erst ermöglichen." (p. 67).

"Still, in the first place, exactly these invariants are, cybernetically speaking, enabling a stabilization of the relationship between humans and their environment and between humans themselves."

Klaus is trying to derive the possibility of objective knowledge (i.e., knowledge that truly reflects reality) by considering convergent sequences of models and invariants appearing in these sequences. First, on p. 214 Klaus introduces a very specific sequence of models:

"subject S reflecting on the object O";

"subject S' reflecting on the subject S reflecting on the object O";

"subject $S$ " reflecting on the subject $S$ ' reflecting on the subject $S$ reflecting on the object O"; etc.

"In diesem Falle verschwindet die Subjektivität, wenn wir die Invarianten finden, die den einzelnen subjektiven Abbildungen zugrunde liegen. ... Selbstverstandlich findet dabei ein fortschreitend tieferes Eindringen in das Wesen der Sache statt.“ (p. 214)

"In this situation, the subjectivity disappears when we find the invariants that underlie the particular subjective reflections. ... Certainly, thereby, a progressively deeper penetration into the nature of the matter is taking place." 
According to Klaus, the most fundamental invariant standing behind the different systems of reference is "what $\mathrm{O}$, in fact, is" [was O tatsächlich ist, p. 218].

On p. 226 Klaus considers sequences of models in a more abstract setting. Let us denote by $S_{i}^{\prime}$ the sequence of models [individuelle, subjektive Ensembles] that are trying to represent an "objective system" $O$. If this sequence is created in a process of "continuous improvement" [ständige Verbesserung], then (as Klaus concludes), $\lim S_{i}^{\prime}=O$.

Stachowiak (1973) extrapolates Klaus's argument as follows:

"Nun wird man Klaus so interpretieren dürfen, daß keineswegs nur eine bestimmte, von $O_{1}$ ausgehende Modell-Iteration die Approximation an das "objektive" Original $O_{1}$ leistet. Klaus scheint zu meinen, daß jede von $O_{1}$ ausgehende Modellfolge, sofern nur "echt" wissenschaftlich modelliert wurde, auf das "Wesen der Sache" führen müsse, und zwar dies bei aller geschichtlichen Bedingtheit der modellbildenden Methoden. Hieraus folgt, das alle solchen $O_{1}$-Iterationsfolgen untereinander konvergent sein und ein gemeinsames Grenzmodell haben müßten, das das Original - dasjenige, was $O_{1}$, "tatsächlich ist“" - vollständig und unverfälscht wiedergibt.” (p. 299)

"Now, one would be allowed to interpret Klaus as follows: in no way, is an approximation to the "objective" original $O_{1}$ given only by a single model iteration starting at $O_{1}$. Klaus seems to think that every model sequence starting at $O_{1}$, as far as we are modeling "truly" scientifically, should lead us to the "nature of things", and this - despite all the historic relativity of model-building methods. It follows from this that all such $O_{1}$-iteration sequences should be mutually convergent and should possess a common limit-model, reproducing the original - what $O_{1}$, "in fact, is" - in a complete and undistorted way."

In the end, Stachowiak qualifies dialectical materialism promoted by Klaus as a "dialectically weakened" [ "dialektisch" abgeschwächte, p. 299-300] materialistic version of realism, but still speculative and dogmatic as any realism is:

"Die Setzung absoluter und subjektfrei objektiver Gegebenheiten kann nur spekulativ sein - oder sie beruht auf bloßer, unmittelbarer Glaubensüberzeugung." (p. 300)

"The setting of absolute and subject-free objective realities can only be speculative - or, they are based on a mere unmediated faith conviction."

"Indes ist natürlich wiederum die Neigung realistischer Philosophen verstehbar, für Forschungs-Konvergenzen und Invarianzen ein "dahinter" befindliches Reales verantwortlich zu machen, und wo dieses bequeme, über lange Zeiten wissenschaftlich-philosophischer Erkenntnisbemühungen hinweg verwendete Denkmodell lediglich als Hypothese, Orientierungshilfe u. dgl. aufgefast wird, bestehen vom Standpunkt kritisch-rationalen Philosophierens keine Einwände.” (p. 300-301)

"However, naturally, again understandable is the tendency of realistic philosophers to make some reality located "behind" as responsible for research convergences and invariants, and where this convenient model of thinking, applied during a long time of 
scientific-philosophical cognitive efforts, is considered as a mere hypothesis, as an aid of orientation, or similar, there [against it] no objections can be raised from the standpoint of critically-rational philosophizing."

"Wie soll Aufsummierung vieler relativer Wahrheiten eine absolute Wahrheit ergeben?" (p. 302)

"How should a summation of many relative truths produce an absolute truth?"

"Wie immer hiernach "Dialektik" zu beurteilen ist: sie bietet keinen Rechtfertigungsgrund für die Annahme "überpragmatischer" Möglichkeiten der Originalerschließung." (p. 303)

"As ever, according to this, "dialectics" must be qualified as follows: it does not provide any justification for assuming "over-pragmatic" possibilities of the access to originals."

Despite this critical assessment, Klaus must be acknowledged as the author of an idea that is very important, but is largely ignored in the modern philosophy of modeling: let us analyze model sequences that appear as science progresses, and let us try to detect invariants that persist in these sequences. For obvious reasons, Klaus declared this idea as justifying the accessibility of "what $\mathrm{O}$, in fact, is", i.e. of an absolute truth in the sense of the representation/reflection-realism. But, in a modern setting, it could be used as a minimalist definition of truth: doesn't truth consist simply of invariants of successful model-building? Remember Craik's: "we should try [it] out as long as it works".

\subsection{A tribute to Herbert Stachowiak (1973)}

Stachowiak's work is completely ignored by philosophers writing in English.

Stachwiak's work on modeling started with two papers, published in 1957 and 1965. His first book (1965) contains a detailed analysis, from a cybernetics perspective, of the available data on the mechanisms of human cognition, but not yet a general concept of modeling. When writing this first book, he was not yet aware of the Apostel's (1961) paper, as noted on p. 4 of Stachowiak's main book (1973).

In his main book "Allgemeine Modelltheorie" (1973, "General Theory of Models"), Stachowiak refers to Apostel (1961), acknowledging that

"L. Apostel hat schon 1961 ein gleichfalls umfassendes, und zwar ebenfalls abbildungstheoretisches Modellkonzept entwickelt." (p. 4)

"L. Apostel has developed, already in 1961, an equally all-embracing and likewise representation/reflection-theoretical concept of models."

In Sections 1.1 and 1.2 of the book, Stachowiak presents his "notes on the history of thought" [denkgeschichliche Notizen] showing the history of skeptical arguments in the 
philosophy of cognition, and observing how "philosophical thought is moving more and more away from the myth" [das philosophische Denken dem Mythos mehr und mehr entfremdet $]$ (p. 8). Section 1.2 is named "Säkularisierung der Erkenntnis", I prefer to translate this as "Demystification of cognition".

According to Stachowiak, the most important conclusion from this demystification process is the impossibility of ultimate decision-free justifications [Unmöglichkeit von entscheidungs-freien Letztbegründungen, p. 45]. As noted by Wolfgang Stegmüller (1954, Section 1.4): to avoid infinite regress, circularity and/or self-refuting, any justification process must be stopped at some point by taking a personal decision to accept or reject. The consequence is the "three-fold pragmatic relativization" [dreifache pragmatische Relativierung, p. 133] of the theory of cognition. Namely, in principle, cognition is:

a) user-dependent (person- or robot-dependent);

b) intention-dependent;

c) time-dependent (progressing).

Adoption of this conclusion is called "the pragmatic decision" [der pragmatische Entschlu $\beta$, p. 50]. Accordingly, for Stachowiak (see Section 1.2.4), the top achievements of the entire past philosophy of cognition are: a) Popper's critical rationalism (praised and criticized by Stachowiak), and b) "holistic decision-pragmatism" [holistische Dezisionspragmatismus, p. 39] proposed by Morton White in 1956.

At this point, in Section 1.3, Stachowiak proposes "the model-based concept of cognition", or "modelism" [das Modellkonzept des Erkenntnis, Modellismus], as the result of the above-mentioned three-fold relativization:

\footnotetext{
"Das Modellkonzept der Erkenntnis greift den Abbildgedanken der klassischen Erkenntnistheorie auf, relativiert ihn jedoch im Sinne des pragmatischen Entschlusses. Hiernach ist alle Erkenntnis Erkenntnis in Modellen oder durch Modelle, und jegliche menschliche Weltbegegnung überhaupt bedarf des Mediums "Modell": indem sie auf das - passive oder aktive - Erfassen von etwas aus ist, vollzieht sie sich relativ zu bestimmten Subjekten, ferner selektiv - intentional selektierend und zentrierend - und in je zeitlicher Begrenzung ihres Original-Bezuges.” (p. 56)
}

\footnotetext{
"The model-based concept of cognition takes the representation/reflection idea of the classical theory of cognition, but relativizes it in the sense of the pragmatic decision. Accordingly, all of cognition is cognition in models or by means of models, and in general, any human encounter with the world needs a "model" as the mediator: focusing on - active or passive - comprehension of something, it [cognition] proceeds relative to certain subjects, further selective - intentionally selecting and centering - and depending on the temporal restriction of its relation to the original."
}

Thus, here, Stachowiak is promoting the idea that models are ubiquitous in cognition.

However, at this point, he does not yet present a precisely defined concept of models, except "the representation/reflection idea of the classical theory of cognition, relativized in the sense of the pragmatic decision". So, what is for him a model at this point? 
"Modell ist Newtons Partikelmechanik ebenso wie Rankes Weltgeschichte oder Hölderlins Hyperion. ... Auch das umfassende philosophische System,... alles dies ist "Modell", hinsichtlich seiner "Objektivität" von der exakten naturwissenschaftlichen Theorie nur graduell unterschieden.” (p. 56-57)

“Newton's particle mechanics, as well as Ranke's Weltgeschichte, or Hölderlin's Hyperion.... The embracing philosophical system as well, ... all these are "model", and, in respect of its "objectivity", it differs only gradually from the exact scientific theory."

Thus, Stachowiak does not separate models from theories, but he does qualify as models not only Newton's particle mechanics, but also (an extremely advanced position!) historical texts (such as Weltgeschichte in 6 volumes, by Leopold von Ranke), works of fiction (such as Hyperion, a novel by Friedrich Hölderlin), and even philosophical systems. And "in respect of its objectivity, all this differs only gradually from the exact scientific theory"!

Only later, in Section 2, does Stachowiak propose his version of "the general concept of model" [der allgemeine Modellbegriff]. He refers to the results of his own inspection of the various senses in which the term "model" is used in science, engineering and art (p. 128-130). He decides to leave out only one of these senses: persons as "models" for the work of art.

As a result, Stachowiak formulates in Section 2.1.1 the three principal features [Hauptmerkmale] of his general concept of model:

1) Representation/reflection feature [Abbildungsmerkmal]:

"Modelle sind stets Modelle von etwas, nämlich Abbildungen, Repräsentationen natürlicher und künstlicher Originale, die selbst wieder Modelle sein können.” (p. 131)

"Models are models of something, namely, [they are] reflections, representations of natural and artificial originals, that can themselves be models again."

After this, a long text follows - on the problem of mapping between the attributes of originals and their models. Here, Stachowiak seems to be orienting us to modeling-bysimplification only.

2) Reduction feature [Verkürzungsmerkmal]

"Modelle erfassen im allgemeinen nicht alle Attribute des durch sie repräsentierten Originals, sondern nur solche, die den jeweiligen Modellerschaffern und/oder Modellbenutzern relevant scheinen." (p. 132)

"Models, in general, do not cover all the attributes of the originals they are representing, but only those [attributes] that seem relevant to the actual model creators and/or model users."

Thus, again, Stachowiak seems to be orienting us to modeling-by-simplification.

3) Pragmatic feature [Pragmatisches Merkmal] 
"Modelle sind ihren Originalen nicht per se eindeutig zugeordnet. Sie erfüllen ihre Ersetzungsfunktion a) für bestimmte - erkennende und/oder handelnde, modellbenutzende - Subjekte, b) innerhalb bestimmter Zeitintervalle und c) unter Einschränkung auf bestimmte gedankliche oder tatsächliche Operationen.

... Modelle sind nicht nur Modelle von etwas. Sie sind auch Modelle für jemanden, einen Menschen oder einen künstlichen Modellbenutzer. Sie erfüllen dabei ihre Funktionen in der Zeit, innerhalb eines Zeitintervalls. Und sie sind schließlich Modelle zu einem bestimmten Zweck.” (p. 132-133)

"Models are not assigned per se uniquely to their originals. They perform their replacement function: a) for definite - cognitive and/or handling, model-using - subjects, b) within definite time intervals, c) under restrictions of definite operations of thought or fact.

... Models are not only models of something. They are also models for somebody, a human or an artificial model user. They perform thereby their functions in time, within a time interval. And finally, they are models for a definite purpose."

Thus, Stachowiak emphasizes explicitly replacing and purpose as the principal features of modeling. And he considers robots as possible model users as well.

"Der Gewinn dieser Vorgehensweise liegt auf der Hand: Modellseitig gewonnene Einsichten und Fertigkeiten lassen sich - bei Erfülltsein gewisser Transferierungskriterien - auf das Original übertragen, der Modellbildner gewinnt neue Kenntnisse über das modellierte Original, ...” (p. 140)

"The advantage of this way of proceeding is evident: insights and skills obtained on the model-side can be - certain transference criteria satisfied - transferred to the original, [in this way] the model-builder obtains a new knowledge about the modeled original, ..."

Minsky (1965) expressed this idea simply as "a model of A is used in place of A to answer questions about A".

Later, on p. 323, Stachowiak presents the modeling relationship as a five-part predicate $\operatorname{Mod}(M, O, U, t, P)$, connecting the model $\mathrm{M}$, the original (target) system $\mathrm{O}$, the user $\mathrm{U}$, the time interval $\mathrm{t}$, and the purpose $\mathrm{P}$. This formulation may have been inspired by Apostel's (1961) four-part modeling predicate $R(U, P, M, O)$, as stated above. Apostel did not include the time dimension.

In the remaining subsections of Chapter 2, Stachowiak considers various classes of models. Surprisingly, many of the instances mentioned here violate the above-stated "reduction feature" (modeling-by-simplification). The first of such cases appears in Section 2.2.3.1 "Static mechanical models":

“... das Raumgittermodell eines Kristalls, das statisch-mechanische Demonstrationsmodell etwa des Uranium 235-Atoms..." (p. 176)

“... the space-lattice model of a crystal, the static-mechanical demonstration model, for instance, of the uranium-235 atom..." 
In fact, here we have models-inventions of not-fully-observable "originals", for which an "attribute mapping" is impossible. (Unless these demonstration models are meant to be obtained by visualization from some other models such as the corresponding mathematical models.)

One of the examples mentioned by Stachowiak rises an interesting question about $\mathrm{hu}$ man evolution as a model inspired by Darwin's theory of evolution:

“... das Modell eines Prähominiden (etwa nach K. P. Oakley und G. Heberer für Plesianthropus) hat zum Original ein aus der weitgehend spekulativen Kombination und Ergänzung von Informationsfragmenten aufgebautes Vorstellungsgebilde.” (p. 176, 179)

“... the model of a pre-hominide (for example, of the Plesianthropus, according to K. P. Oakley and G. Heberer) has as its original a notion built from the widely speculative combination and extension of information fragments."

Plesianthropus is meant here as a (theoretical) reconstruction of a particular fossil scull found in 1947. I would not call such theoretical reconstructions "originals". The entirety of human evolution as a model of all the relevant fossil remains ever found seems to be a more productive concept.

In Section 2.2.3.2 "Dynamic mechanical models", Stachowiak refers to two other modelsinventions of not-fully-observable "originals": a) Maxwell's electromagnetic theory, the mathematical structure of which was obtained by way of analogy with fluid dynamics; and b) the planetary model of atoms, also obtained by means of analogy, and replaced later by a non-visual mathematical formalism - the "atom-system of quantum mechanics" (p. 184).

In Section 2.2.3.5 "Electro-chemical models", Stachowiak refers again to a modelinvention: the experiment invented by Stanley Miller to show, in principle, how amino acids could have been created by electric discharges in the early atmosphere of Earth (p. 189).

On p. 208-209 two more arguments are mentioned in favor of the thesis "all cognition is cognition in models":

"Die ganze Modellhaftigkeit menschlicher Weltbegegnung wie zwischenmenschlicher Kommunikation ist gleichsam eingefaltet bereits im Modellcharakter des Perzeptionsgeschehens." (p. 208)

"An dem Modellcharakter der Perzeptionsgebilde kann auch der Umstand nichts ändern, daß der Zugang zur Originalseite, d. h. zu den Beschaffenheiten der Signalkonstellationen der Außenwelt, immer nur über die Bildung interner Außenweltmodelle möglich ist." (p. 209)

"All the model-boundedness of human encounter with the world as well as the interhuman communication is equally involved already in the modeling character of the perception process."

"The modeling character of perception forms is also not changed by the circumstance that the access to the original-side, i.e. to the properties of signal constellations from 
the external world, it is only always possible via the building of internal models of the external world."

In Section 2.3.3.3 "Metaphysical models", Stachowiak considers "total models" [Totalmodelle, p. 238-239], i.e. models of the entire universe, as opposed to "aspect models" or "partial models" [aspektive Teilmodelle]. He refers to the work of Ernst Topitsch (1958), who consistently applied the term "models" [Modelle, Modellvorstellungen] to metaphysical notions and concepts (approximately 200 times throughout his 1958 book). According to Topitsch, these models were created mainly by means of anthropomorphic, biomorphic, technomorphic, and/or sociomorphic analogies. Stachowiak's formulation:

\footnotetext{
"Andere Kosmos-Modelle bedienen sich "soziomorpher" Analogien, dergestalt vor allem, daß die Weltordnung nach dem Vorbild der Staatsordnung begriffen wurde.” (p. 239)

"Other models of the universe draw on "sociomorphic" analogies, in such a manner, first of all, that the world order is understood after the pattern of the government system." (The idea of anthropomorphic analogies as a means for creating religious concepts was already considered in Kant's work, and Friedrich Karl Forberg consistently defended the legitimacy of this idea. For details, see Vaihinger (1911), Parts IIIA and IIIB.)
}

At the end of Section 2.3.3.3, Stachowiak qualifies the "classical representation/ reflectionrealism" [klassischer Abbildungsrealismus] from the view-point of his model theory:

“... kein Mensch anders als über Modellbildungen sein Erkenntnisobjekt erschließen kann und ein absoluter, d. h. nicht pragmatisch zu relativierender Beurteilungsstandpunkt gegenüber der Original-Modell-Relation nicht nachweisbar ist.” (p. 240)

“... no one can access his/her object of cognition other than by means of modelbuilding, and an absolute, i.e. pragmatically non-relativized assessment standpoint towards the original-model-relationship cannot be verified."

Thus, realism represents a non-attainable ideal [ein unerfüllbares Ideal].

\section{Conclusions}

The concise and extremely elegant definition of modeling proposed by Rothenberg (1989), in a sense, summarizes the above exposition of history:

"Modeling in its broadest sense is the cost-effective use of something in place of something else for some cognitive purpose. ...

Modeling underlies our ability to think and imagine, to use signs and language, to communicate, to generalize from experience, to deal with the unexpected, and to make sense out of the raw bombardment of our sensations." (p. 75) 
A tribute to Jeff Rothenberg (1989)

Rothenberg explicitly emphasizes replacing and purpose as the principal features of modeling:

\begin{abstract}
"Modeling in its broadest sense is the cost-effective use of something in place of something else for some [cognitive] purpose. It allows us to use something that is simpler, safer, or cheaper than reality instead of reality for some purpose. A model represents reality for the given purpose; the model is an abstraction of reality in the sense that it cannot represent all aspects of reality. This allows us to deal with the world in a simplified manner, avoiding the complexity, danger and irreversibility of reality." (p. 75, the attribute "cognitive", missing in the manuscript, was added in the published version).
\end{abstract}

Thus, Rothenberg's emphasis is on modeling-by-simplification, but he admits also modelingby-invention. For example, he refers to medieval blood-letting as based on an inappropriate model. Inappropriate models cannot be "discovered", they can only be invented.

Rothenberg acknowledges the ubiquitous role of modeling in cognition as well:

\begin{abstract}
"Modeling underlies our ability to think and imagine, to use signs and language, to communicate, to generalize from experience, to deal with the unexpected, and to make sense out of the raw bombardment of our sensations. It allows us to see patterns, to appreciate, predict, and manipulate processes and things, and to express meaning and purpose. In short, it is one of the most essential activities of the human mind. It is the foundation of what we call intelligent behavior and is a large part of what makes us human. We are, in a word, modelers: creatures that build and use models routinely, habitually - sometimes even compulsively - to face, understand, and interact with reality." (p. 75)
\end{abstract}

Aren't these two unifying ideas ("modeling as replacing the target for a definite purpose"; and "all of cognition is modeling") worth discussing?

And aren't the following four ideas worth discussing as well?

An important idea is represented in Craik's answer to the question: why, at all, is modeling possible? Because "there are recurrent patterns in reality". The possibility of modeling is built into the structure of the physical universe. Fragments of the universe (models) are "working in the same way in certain essential respects" as some other fragments of the universe (target systems).

Another important idea is Craik's consideration of human language as an experimentally established successful means of model-building.

Also worthy of discussion is Craik's approach to philosophy of mathematics: instead of asking "what kind of thing a number is" or about "real existence' of numbers as such", let us think about the "extreme flexibility" and universality of numbers as a structure, that "renders a far greater number of operations possible than any other single process or model". This is why "numerical symbolism" is ubiquitous in modeling.

Finally, we must acknowledge Klaus as the author of an idea that is very important, but largely ignored in the modern philosophy of modeling: let us analyze model sequences that appear as science progresses, and let us try to detect invariants that persist in these 
sequences. This idea could be used as a minimalist definition of truth: doesn't truth consist simply of invariants of successful model-building? Remember Craik's: "we should try [it] out as long as it works".

\section{References}

Apostel, L. (1960). Towards the formal study of models in the non-formal sciences. Synthese, Volume 12, Numbers 2-3 (1960), 125-161.

Apostel, L. (1961). Towards the formal study of models in the non-formal sciences. In: The Concept and the Role of the Model in Mathematics and Natural and Social Sciences (H. Freudenthal, ed.), D. Reidel: Dordrecht, 1961, 1-37 (reprint of Apostel, 1960)

Barrett, J. A. (2001). Toward a Pragmatic Account of Scientific Knowledge, PhilSci Archive, 498, 7 October 2001, 43 pp.

Bunge, M. (1969). Models in Theoretical Science. Akten des XIV. Internationalen Kongresses für Philosophie, vol. 3, 208-217.

Bunge, M. (1973). Philosophy of Physics. Dordrecht: Reidel.

Cartwright, N. (1983). How the Laws of Physics Lie, Oxford University Press.

Cartwright, N. (1999): The Dappled World: A Study of the Boundaries of Science, Cambridge University Press.

Craik, K. (1943). The Nature of Explanation, Cambridge University Press.

Einstein, A. (1930). Albert Einstein über Kepler. Frankfurter Zeitung, 9. November 1930. (English translation by Sonja Bargmann published in: A. Einstein. Ideas and Opinions. Crown Publishers, New York, 1954, 262-266.)

Fine, A. (1993). Fictionalism. Midwest Studies in Philosophy, 18(1), 1-18.

Frigg, R., Hartmann, S. (2012). Models in Science, The Stanford Encyclopedia of Philosophy (Fall 2012 Edition), Edward N. Zalta (ed.)

Giere, R. N. (1979). Understanding Scientific Reasoning, Holt, Rinehart and Winston.

Gregory, R. L. (1983). Forty years on: Kenneth Craik's The Nature of Explanation (1943). Perception, 1983, vol. 12, 233-238.

Johnson-Laird, P. N. (1980). Mental Models in Cognitive Science, Cognitive Science, 4, 71-115.

Klaus, G. (1966). Kybernetik und Erkenntnistheorie, VEB Deutscher Verlag der Wissenschaften, Berlin.

Minsky, M. (1961). Steps toward Artificial Intelligence. Proceedings of the IRE, 49: 8-30.

Minsky, M. (1965). Matter, Mind and Models. Proceedings of the IFIP Congress 65, 1: 45-49.

Müller, R. (1983). Zur Geschichte des Modelldenkens und des Modellbegriffs. In: Modelle Konstruktion der Wirklichkeit, ed. Stachowiak, H., München: Fink, 17-86 (extended online version available, English translation included).

Peirce, C. S. (1877). The Fixation of Belief. Popular Science Monthly, 12 (November 1877), $1-15$.

Peirce, C. S. (1878). How to Make Our Ideas Clear. Popular Science Monthly, 12 (January 1878), 286-302.

Rosenblueth, A., Wiener, N. (1945). The Role of Models in Science, Philosophy of Science, 12(4), 316-321.

Rothenberg, J. (1989). The Nature of Modeling. In: Artificial Intelligence, Simulation, and Modeling, Wiley and Sons, 75-92.

Simon G. (2014). Leben und Wirken Hans Vaihingers. In: Neuber, M. (Hg.), Fiktion und Fiktionalismus. Beiträge zu Hans Vaihingers "Philosophie des Als Ob", Studien und Materialien zum Neukantianismus, Bd. 33, 21-41. 
Stachowiak, H. (1965). Denken und Erkennen im kybernetischen Modell, Wien/New York: Springer.

Stachowiak, H. (1973). Allgemeine Modelltheorie, Wien: Springer.

Stegmüller, W. (1954). Metaphysik - Wissenschaft - Skepsis, Frankfurt/Main-Wien: HumboldtVerlag. Quoted from the second edition: Metaphysik, Skepsis, Wissenschaft. Zweite, verbesserte Auflage, Berlin, Heidelberg, New York: Springer, 1969.

Suárez, M. (2009). Scientific fictions as rules of inference. In: Suárez, M. (Ed.), Fictions in Science. Philosophical Essays on Modeling and Idealization, Routledge, 2009, 158-178.

Suppes, P. (1960). A Comparison of the Meaning and Uses of Models in Mathematics and the Empirical Sciences, Synthese, 12 (2-3), 287-301.

Topitsch, E. (1958). Vom Ursprung und Ende der Metaphysik. Eine Studie zur Weltanschauungskritik, Springer-Verlag, Wien.

Vaihinger, H. (1911). Die Philosophie des Als Ob. System der theoretischen, praktischen und religiösen Fiktionen der Menschheit auf Grund eines idealistischen Positivismus, 7. und 8. Auflage, Verlag von Felix Meiner, Leipzig, 1922, 804 pp.

Vaihinger, H. (1924). The Philosophy of "As if". A System of the Theoretical, Practical and Religious Fictions of Mankind. Translated by C. K. Ogden, Routledge. Quoted from the 2009 reprint.

Wikipedia (2018). Gertraudenfriedhof (Halle). Updated March 29, 2018.

Received June 22, 2018 , revised September 10, 2018, accepted September 12, 2018 